\title{
IDENTIFICAÇÃO DE PROGRAMAS DE QUALIDADE APLICADOS EM ALGUNS LATICÍNIOS DO OESTE DE SANTA CATARINA
}

\section{Identification of quality programs applied to some dairy industries in the west of Santa Catarina}

\author{
Maria Regina Thomaz ${ }^{I}$, Rosana da Silva ${ }^{I}$, Nédio Luiz Verdi ${ }^{I}$, Josiane Maria Muneron de \\ Mello $^{l}$, Marcelo Fabiano Costella ${ }^{l}$, Francieli Dalcanton ${ }^{1 *}$
}

\section{RESUMO}

O leite é considerado um dos alimentos mais completos e consumidos por grande parte da população. Nos últimos anos as exigências das legislações e do mercado consumidor pela melhoria da qualidade no setor lácteo têm sido constantes. Os Laticínios estão investindo cada vez mais na adoção de normas e ferramentas com foco em gestão da qualidade e segurança de alimentos, garantindo a sua sobrevivência e competitividade no mercado globalizado. O presente trabalho teve como objetivo identificar a situação da implantação de sistemas de gestão da qualidade em Laticínios localizados no oeste de Santa Catarina e analisar as iniciativas para garantir a qualidade dos produtos processados. Foi realizado um estudo de caso, sendo que o método survey foi utilizado para levantamento de dados por meio de um questionário aplicado a quatro Laticínios. Os Laticínios em estudo utilizam os programas básicos do sistema de gestão da qualidade exigidos pela legislação brasileira vigente podendo-se citar as Boas Práticas de Higiene (BPH), as Boas Práticas de Fabricação (BPF), a Análise de Perigos e Pontos Críticos de Controle (APPCC) e o Monitoramento Interno de Pragas (MIP). Além disso, demonstram a preocupação em manter e adequar o sistema de qualidade a fim de proporcionar a segurança de seus produtos, a padronização e a organização dos processos, para garantir a competitividade e a qualidade dos produtos finais.

Palavras-chave: normativa; qualidade do processo; segurança de alimentos.

1 Universidade Comunitária da Região de Chapecó, Servidão Anjo da Guarda, 295-D, Efapi, 89809-900, Chapecó, SC, Brasil. E-mail: fdalcanton@unochapeco.edu.br

* Autor para correspondência 


\begin{abstract}
Milk is considered one of the most complete foods and consumed by a large part of the population. In recent years the demands of legislation and the consumer market for improving quality in the dairy sector have been constant. Dairy products are increasingly investing in the adoption of standards and tools focused on food quality and safety management, guaranteeing their survival and competitiveness in the globalized market. The present work aimed to identify the situation of the implementation of quality management systems in dairy industries located in the West of Santa Catarina state and to analyze the initiatives to guarantee the quality of processed products. A case study was carried out, and the survey method was used to collect data through a questionnaire applied to four dairy products. The dairy products under study apply the basic tools of the quality management system required by current Brazilian legislation, such as Good Hygiene Practices, Good Manufacturing Practices, Hazard Analysis and Critical Control Points and Internal Pest Monitoring, concern to maintain and adapt the quality system of its products, providing food safety, standardization and organization of processes, which ensures the competitiveness and safety of products.
\end{abstract}

Keywords: regulation; quality process; food safety.

\section{INTRODUÇ̃̃̃O}

Desde os primórdios da era industrial, as empresas têm-se preocupado com a qualidade dos produtos produzidos e, atualmente, podese considerar a preocupação em todos os processos pelos quais as empresas passam para garantir a satisfação dos consumidores. A qualidade dos serviços e produtos é fator chave para a eficácia, sendo estes fatores a base para o sucesso ou fracasso das organizações (SCARDELATO et al., 2017). No setor alimentício a qualidade é vital, além de tornar a empresa competitiva, está diretamente relacionado com a saúde do consumidor (SANTOS et al., 2013).

Nas indústrias de Laticínios, além das tecnologias adequadas à fabricação dos produtos, o aporte tecnológico deverá estar presente, por meio da adoção de práticas higiênicas, implementação de mudanças na tecnologia da produção, métodos de conservação e inovação na produção de derivados. As indústrias devem tornar-se parte obrigatória do sistema de controle de qualidade (FIGUEIREDO et al., 2016).

Além disso, as indústrias devem estar sempre prontas para se adequarem às mudanças na legislação como, por exemplo, às recentes alterações nas normas de produção de leite estabelecidas pelo Ministério da Agricultura, Pecuária e Abastecimento (MAPA), por meio das Instruções Normativas $n^{\circ} 76$ (IN 76/2018) e 77 (IN 77/2018) de 26 de novembro de 2018 (BRASIL, 2018a; BRASIL, 2018b). Muitas alterações importantes foram estabelecidas nas recentes normativas, tanto para os produtores, quanto para a indústria, gerando muitos desafios em toda cadeia leiteira.

O leite possui um alto valor nutricional, sendo um dos principais alimentos consumidos pelo homem. Apesar de suas vantagens, pode acarretar agravos à saúde, sobretudo quando produzido, armazenado e processado em condições higiênico-sanitárias inadequadas (ORNELLAS et al., 2017). O sistema de coleta tem grande importância e está diretamente ligado segurança de alimentos (FRANÇA et al. 2015).

Dados de pesquisa realizada pelo 
Instituto Brasileiro de Geografia e Estatística (IBGE, 2018) informam que no $2^{\circ}$ trimestre de 2018, a aquisição de leite cru feita pelos estabelecimentos que atuam sob algum tipo de inspeção sanitária (Federal, Estadual ou Municipal) foi de 5,47 bilhões de litros, representando uma queda de $3,2 \%$ em relação à quantidade adquirida no $2^{\circ}$ trimestre de 2017. De acordo com o Departamento de Agricultura dos Estados Unidos (United States Department of Agriculture - USDA), o Brasil ocupou a sétima posição no ranking mundial de produção de leite em 2017.

Projeções realizadas pela FAO (Food and Agriculture Organization) indicam que o consumo de lácteos aumentará significativamente até 2030 . Assim, obrigando a cadeia produtiva a profissionalizar-se, com ferramentas e técnicas que aumentam a produtividade de forma sustentável, com foco na qualidade e segurança dos alimentos. Desta maneira, as indústrias de alimentos poderão se manter competitivas no mercado consumidor, atendendo as expectativas do cliente e exigências dos órgãos fiscalizadores (SANTOS; LIMA, 2011).

A segurança dos alimentos tem como base legal a Portaria $n^{\circ}$ 368/1997 (BRASIL, 1997), que estabelece as Boas Práticas de Fabricação (BPF), que abrangem um conjunto de medidas que devem ser adotadas, a fim de garantir a qualidade sanitária dos alimentos. Já os Procedimentos Padrões de Higiene Operacional (PPHO) (BRASIL, 2003) são procedimentos desenvolvidos, implementados e monitorados, que buscam estabelecer uma rotina de segurança dos alimentos, além de evitar a contaminação direta ou cruzada e a adulteração do produto (SALCEDO, 2016). Os manuais de BPF e PPHO são documentos complementares e fundamentais para garantir a qualidade e higiene dos produtos produzidos.

Além disso, o Sistema de Análise de Perigos e Pontos Críticos de Controle (APPCC) (BRASIL, 1998), é um sistema de análise que identifica perigos específicos, além de medidas preventivas para o controle dos mesmos. O programa de BPF e PPHO são considerados pré-requisitos para a implantação do sistema de APPCC.

Em setembro de 2005 foi enunciada a Norma Internacional "ISO 22000:2005 Food Safety Management Systems - Requirements for any Organization in the Food Chain" (CARMEN; VIJANDE, 2014; BRASIL, 2006). A ISO 22000 especifica os requisitos para um sistema de gestão da qualidade quando uma organização do ramo alimentício deve demonstrar a capacidade de controlar os riscos relacionados com a segurança dos alimentos, a fim de assegurar que o alimento é seguro no tempo determinado ao consumo humano.

Com o objetivo de padronizar a inspeção e definir critérios para verificação das BPF, PPHO e APPCC foram estabelecidos, em 2009, os Programas de Autocontrole (PACs), por meio dos Ofícios Circulares $n^{\circ} 07$ e $\mathrm{n}^{\circ} 24$ de setembro de 2009 , posteriormente normatizado na Norma Interna $\mathrm{n}^{\circ} 1 \mathrm{de}$ 08 de março de 2017 (BRASIL, 2017a) e pelo Regulamento de Inspeção Industrial e Sanitária de Produtos de Origem Animal (RIISPOA) (BRASIL, 2017b). O MAPA exige a implementação desses Programas ou de outros que se demonstrem eficazes na garantia da qualidade do produto final (BRASIL, 2017b).

Neste sentido, o presente trabalho teve como objetivo identificar a situação da implantação de sistemas de gestão da qualidade e analisar as iniciativas para garantir a qualidade dos produtos processados em quatro Laticínios localizados na região Oeste de Santa Catarina.

\section{MATERIAL E MÉTODOS}

O presente estudo foi realizado em Laticínios de grande, médio e pequeno porte, 
localizados na região Oeste de Santa Catarina no ano de 2016. Esta região foi escolhida por possuir grande número de Laticínios e elevado número de agricultores que utilizam a atividade leiteira como meio de subsistência da família. O questionário desenvolvido nesta pesquisa foi submetido a análise de 17 Laticínios que pertencem a região e destes, 4 indústrias responderam a pesquisa. Apesar de não ser uma amostragem estatística decidiuse apresentar este estudo, pois os dados encontrados são relevantes para área leiteira. As empresas foram denominadas de empresa A, B, C e D.

O método de pesquisa utilizado foi o survey, que consiste em uma modalidade de pesquisa baseada na coleta de informações por meio de questionário, destinados a obter informações específicas das empresas entrevistadas (FREITAS et al., 2000). Foi elaborado um questionário, contendo questões abertas e fechadas, dividido em categorias representativas do resultado da utilização de um sistema de garantia da qualidade do produto, enviado por meio eletrônico e posteriormente realizado contato telefônico com o responsável do controle de qualidade repassando informações sobre a importância do estudo para os dezessete Laticínios. Os questionamentos foram respondidos em 3 categorias: I - implantado, PI - parcialmente implantado e NI - não implantado, sendo que as questões que compõem o questionário estão apresentadas a seguir:

1 Perfil dos Laticínios: nome, razão social, localização, endereço, responsável pelas informações;

2 Caracterização do Laticínio: tipo e tamanho da empresa, volume processado diariamente, tempo em que a empresa atua no mercado, frequência de recebimento, produtos produzidos, informações sobre serviços terceirizados, grau de instrução dos funcionários e os profissionais que atuam no Laticínio;
3 Qualidade do processo: comprometimento da direção e a existência de um setor específico para o controle de qualidade; se houve mudanças para adequação da IN 51/2002 para a IN 62/2011, análises realizadas na recepção do leite. Além disso, questionou-se quais as metodologias e ferramentas/programas: Inspeção por amostragem, Programa 5S, Boas Práticas de Higiene (BPH), BPF, APPCC, Monitoramento Interno de Pragas (MIP), PPHO, PDCA (Plan, Do, Check, Action), Controle Estatístico de Processo (CEP), Norma ISO 9001, Norma ISO 14001, Norma ISO 22000 e Norma OSHAS 18000 implantadas (I), parcialmente implantadas (PI) e não implantada (NP) no Laticínio. Além disso, por meio de resposta aberta, perguntou-se qual a razão da busca de normas do sistema de gestão da qualidade, além de vantagens, desvantagens e qual a importância da aplicação dos programas de qualidade.

Buscou-se identificar a abordagem de cada empresa voltada para a qualidade, as características individuais e as ações realizadas no controle de todo o processo. Realizou-se um comparativo do emprego da gestão da qualidade entre as empresas que responderam o questionário por meio de quadros e tabela.

\section{RESULTADOS E DISCUSSÃO}

\section{Perfil dos Laticínios}

A Tabela 1 apresenta o perfil dos Laticínios, todos localizados no estado de Santa Catarina, Brasil, caracterizados pelo funcionário que respondeu ao questionário (identificado na tabela pela sua função) e se a localização é no meio rural ou urbano. Esta foi a parte inicial do questionário para 
conhecimento das empresas que compõem essa pesquisa.

\section{Caracterização dos Laticínios}

No Quadro 1 está exposta a caracterização de cada Laticínio, referente ao volume de leite processado diariamente, o período em que o produto é recebido no Laticínio para o processamento, porte da empresa, o destino que é dado ao leite após a chegada ao Laticínio, os profissionais que atuam nos Laticínios e qual o tipo de registro que cada Laticínio possui.

Observa-se no Quadro 1 que o Laticínio A é uma grande empresa, com processamento de 1.500.000 L de leite durante $24 \mathrm{~h}$ por dia, o Laticínio B é de porte médio com capacidade de $200.000 \mathrm{~L}$ e recebe o leite durante $18 \mathrm{~h}$ por dia, enquanto os Laticínios C e D são de pequeno porte, sendo que o $\mathrm{D}$ produz na própria empresa $70 \%$ do leite processado diariamente e o Laticínio C processa 78.000 L de leite.

Os produtos dos Laticínios A, B e $C$ possuem registro no SIF do MAPA e disponibilizam seus produtos no mercado nacional, sendo que $\mathrm{A}$ e $\mathrm{C}$ atendem também o mercado internacional. O SIF vinculado ao Departamento de Inspeção de Produtos de Origem Animal (DIPOA) é o responsável pela inspeção e fiscalização de produtos de origem animal, visando garantir produtos com certificação sanitária e tecnológica para o consumidor brasileiro, respeitando as legislações nacionais e internacionais vigentes (BRASIL, 2016).

O Laticínio D atende o mercado local, o estado de Santa Catarina e também outros estados brasileiros, visto que possui registro no Serviço de Inspeção Estadual (SIE) e a certificação Sistema Brasileiro de Inspeção de Produtos de Origem Animal (SISBI/ POA) - cujo objetivo é integrar os Serviços de Inspeção Federal, Estadual e Municipal, harmonizando as ações fiscais e uniformizando os procedimentos de inspeção em todo o país. Dessa maneira, garante a segurança dos alimentos independentemente da instância que o inspeciona (BRASIL, 2016).

Observa-se que os Laticínios cumprem com a determinação da legislação de manter profissionais habilitados, como veterinários, tecnólogos de alimentos, proporcionando suporte técnico necessário para a produção de derivados lácteos e também à cadeia produtiva.

\section{Qualidade do processo}

Em todos os Laticínios o departamento de controle de qualidade está atuante, possui

Tabela 1 - Perfil dos Laticínios (meio urbano ou rural) e função do funcionário responsável por preencher o questionário

\begin{tabular}{ccccc}
\hline \multirow{2}{*}{ Perfil } & A & B & Caticínios & D \\
\cline { 2 - 5 } & Encarregado & Responsável & Supervisor & Re produção \\
Função do \\
$\begin{array}{c}\text { responsável } \\
\text { pelo }\end{array}$ & $\begin{array}{c}\text { do laboratório } \\
\text { e controle de } \\
\text { preenchimento }\end{array}$ & $\begin{array}{c}\text { controle de } \\
\text { qualidade }\end{array}$ & $\begin{array}{c}\text { e controle de } \\
\text { qualidade }\end{array}$ & $\begin{array}{c}\text { controle de } \\
\text { qualidade }\end{array}$ \\
\hline Meio & Rural & Rural & Urbano & Rural \\
\hline
\end{tabular}


Quadro 1 - Caracterização dos Laticínios segundo o porte, o volume de leite processado diariamente, a frequência de recebimento de leite e o seu destino, os profissionais que atuam nos Laticínios e o tipo de registro

\begin{tabular}{|c|c|c|c|c|}
\hline \multirow{2}{*}{ Características } & \multicolumn{4}{|c|}{ Laticínios } \\
\hline & $\mathbf{A}$ & B & $\mathrm{C}$ & D \\
\hline Porte & Grande & Médio & Pequeno & Pequeno \\
\hline $\begin{array}{c}\text { Volume de leite } \\
\text { processado } \\
\text { (L/dia) }\end{array}$ & 1.500 .000 & 200.000 & 78.000 & 1.500 \\
\hline $\begin{array}{l}\text { Frequência de } \\
\text { recebimento do } \\
\text { leite (dia) }\end{array}$ & 24 horas & 18 horas & 10 horas & $\begin{array}{l}1 \mathrm{vez} / \text { dia, } \\
70 \% \text { do leite } \\
\text { processado } \\
\text { da própria } \\
\text { Indústria }\end{array}$ \\
\hline Destino do leite & $\begin{array}{l}\text { Bebida láctea, } \\
\text { fermentados, leite } \\
\text { UHT e em pó, } \\
\text { queijo, requeijão e } \\
\text { creme de leite }\end{array}$ & Queijos & $\begin{array}{c}\text { Queijo, } \\
\text { manteiga, } \\
\text { creme de leite } \\
\text { pasteurizado }\end{array}$ & Queijos \\
\hline $\begin{array}{l}\text { Profissionais } \\
\text { que atuam no } \\
\text { Laticínio }\end{array}$ & $\begin{array}{c}\text { Técnico em } \\
\text { Laticínios, } \\
\text { Zootecnista, } \\
\text { Veterinário, Técnico } \\
\text { Agropecuário, } \\
\text { Técnico em } \\
\text { Alimentos, } \\
\text { Engenheiro de } \\
\text { Alimentos }\end{array}$ & $\begin{array}{l}\text { Técnico } \\
\text { Agropecuário, } \\
\text { Técnico em } \\
\text { Alimentos, } \\
\text { Tecnólogo } \\
\text { em Produção } \\
\text { Leiteira, } \\
\text { Veterinário }\end{array}$ & $\begin{array}{l}\text { Técnico em } \\
\text { Laticínios }\end{array}$ & $\begin{array}{l}\text { Tecnólogo } \\
\text { em } \\
\text { Alimentos, } \\
\text { Veterinário }\end{array}$ \\
\hline \multirow{2}{*}{$\begin{array}{l}\text { Registro dos } \\
\text { Produtos }\end{array}$} & \multirow{2}{*}{$\begin{array}{c}\text { SIF (Serviço de } \\
\text { Inspeção Federal) }\end{array}$} & \multirow[b]{2}{*}{ SIF } & \multirow[b]{2}{*}{ SIF } & $\begin{array}{l}\text { SIE (Serviço } \\
\text { de Inspeção } \\
\text { Estadual) }\end{array}$ \\
\hline & & & & $\begin{array}{c}\text { SISBI } \\
\text { (Sistema } \\
\text { Brasileiro de } \\
\text { Inspeção) }\end{array}$ \\
\hline
\end{tabular}


um responsável técnico e a alta direção da empresa está comprometida com a qualidade dos produtos fabricados.

O Laticínio A informou que realiza ou que já realizou modificações para atender aos requisitos da IN 62/2011, vigente na época da realização da pesquisa, porém não forneceu detalhes. O Laticínio B realizou modificações relacionadas ao sistema de refrigeração dos caminhões de coleta de leite e começou a realizar orientações e visitas mensais nos produtores que não atendiam os requisitos da norma.

A empresa $\mathrm{C}$, informou que realizou modificações para atender a IN 62/2011 quanto aos padrões mínimos de contagem de células somáticas (CCS) e contagem bacteriana total (CBT), necessitando realizar orientações e treinamentos para os produtores rurais, capacitando-os para atender os padrões de higiene e qualidade da matéria-prima exigidos na legislação. No Laticínio D não houve necessidade de modificações, pois a indústria foi projetada e implantada para atender as especificações da IN 62/2011. Com a publicação das novas normativas, IN $76 / 2018$ e IN 77/2018, as empresas deverão se adequar novamente para atender os requisitos exigidos e melhorar continuamente a qualidade dos produtos fabricados.

Em relação às análises realizadas na recepção do leite, os Laticínios, $\mathrm{A}, \mathrm{B}, \mathrm{C}$ e $\mathrm{D}$, realizavam o que preconiza a IN 62/2011, quanto aos requisitos físicos, químicos, microbiológicos, de CCS e de resíduos químicos, sendo que a liberação do lote estava condicionada ao atendimento dos padrões da legislação.

Por meio da adequação e aplicação da norma, observou-se a preocupação dos Laticínios participantes da pesquisa em atender aos requisitos legais, garantir a qualidade da matéria-prima com suporte técnico nas propriedades rurais, o transporte adequado e a realização de análises laboratoriais para garantir a qualidade de seus produtos.
A qualidade do leite in natura tem origem da fazenda e é determinada por alguns parâmetros como a baixa $\mathrm{CCS}$, baixas $\mathrm{CTB}$ e pela ausência de resíduos de antibióticos e ou químicos. Para o consumidor este produto deve ser saudável, nutritivo e que não cause doenças ou distúrbios em quem consome. Desta maneira, as práticas de higiene devem ter início ainda na fazenda e posteriormente na industrialização, transporte e comércio, proporcionando assim a segurança de alimentos, pois falhas de higiene na ordenha e manipulação do produto elevam a possibilidade de produto fora dos padrões qualidade (BERSOT et al., 2010).

O Quadro 2 apresenta as principais ferramentas, programas e metodologias de gestão da qualidade empregadas pelas indústrias, e a condição apresentada em cada Laticínio do estudo.

O Laticínio A utiliza as metodologias e ferramentas básicas exigidas pela legislação e ainda possui a norma ISO 9001 implantada. No entanto, as normas ISO 14001 e a ISO 22000 estão parcialmente implantadas, e não possuem registro de qualquer atividade com a norma OSHAS 18000 .

A empresa $\mathrm{A}$ informa que as razões de buscar a implantação das normas do sistema de gestão da qualidade são a melhoria no sistema de qualidade e segurança dos alimentos, padronização e organização dos processos, busca de competitividade, diminuição de custos e adoção de uma norma de padronização internacional. A vantagem na implantação do sistema de gestão é uma maior confiança de clientes e consumidores e a desvantagens ou dificuldades na implantação do sistema de gestão foi o custo para a implantação.

As empresas B, C e D utilizam as metodologias e ferramentas exigidas para os mercados em que atuam e ainda não estão implantando as normas ISO's. A empresa C é a que possui a maior fragilidade no controle de qualidade, pois métodos básicos, como 
por exemplo o 5S, ainda não são implantados por este Laticínio. Também não aplicam a ferramenta PDCA que é a base para a melhoria contínua.

O Laticínio B expõe que buscou as ferramentas da qualidade para proporcionar maior confiança de clientes e consumidores. A vantagem obtida foi maior seriedade e comprometimento dos operadores da empresa na produção de alimentos seguros e sem risco de causar danos à saúde dos consumidores. A dificuldade encontrada esteve relacionada aos seus colaboradores em aceitar mudanças e os novos critérios exigidos para o controle.

Para a empresa $\mathrm{C}$, a razão da implantação parcial das ferramentas e metodologias do sistema de gestão da qualidade é a melhoria na qualidade e segurança dos alimentos, o que resulta em vantagens como maior confiança de clientes e consumidores e a maior seriedade e comprometimento dos operadores do Laticínio na produção de alimentos seguros e sem risco de causar danos à saúde dos consumidores. Para o Laticínio não há desvantagem, apenas dificuldade das pessoas em aceitarem mudanças e os novos critérios exigidos para o controle.

O Laticínio D cita que o motivo pelo qual buscou a implantação das ferramentas da qualidade está relacionado a melhorias no sistema de qualidade, segurança dos alimentos e a busca pela padronização e organização dos processos. A vantagem obtida foi a maior confiança de clientes e consumidores e maior seriedade e comprometimento dos operadores da empresa. A dificuldade encontrada foi falta de aporte técnico específico.

Para Djordjevic et al., (2011) o controle de segurança é responsabilidade conjunta que envolve todos os participantes da cadeia

Quadro 2 - Ferramentas, programas e metodologias da qualidade implantados, parcialmente implantados e não implantados nos Laticínios estudados*

\begin{tabular}{|l|c|c|c|c|}
\hline $\begin{array}{l}\text { Ferramentas/programas/ } \\
\text { metodologia }\end{array}$ & Laticínio A & Laticínio B & Laticínio C & Laticínio D \\
\hline BPH & I & I & I & I \\
\hline BPF & I & I & I & I \\
\hline PPHO & I & I & I & I \\
\hline APPCC & I & I & I & I \\
\hline MIP & I & I & I & I \\
\hline Inspeção por Amostragem & I & I & NI & I \\
\hline Programa 5S & I & I & NI & I \\
\hline PDCA & I & NI & NI & I \\
\hline CEP & I & NI & NI & NI \\
\hline Norma ISO 9001 & I & NI & NI & NI \\
\hline Norma ISO 14001 & PI & NI & NI & NI \\
\hline Norma ISO 22000 & PI & NI & NI & NI \\
\hline Norma ISO 18000 & NI & NI & NI & NI \\
\hline
\end{tabular}

*I - Implantado; PI - Parcialmente Implantado; NI - Não Implantado 
alimentar, dos operadores envolvidos na produção, transformação, comercialização e venda de produtos alimentares (seja para consumo humano ou à alimentação animal), em conjunto com os seus subcontratantes relacionados. $\mathrm{O}$ atendimento as legislações de alimentos no Brasil são a base para um sistema de gestão da qualidade coerente e que propicie uma maior segurança de alimentos (FELTES et al., 2017). No presente estudo verificou-se que os Laticínios cumprem com as legislações básicas mostrando um caminho para aplicação de sistemas mais complexos e que irão fornecer uma qualidade ainda maior dos produtos produzidos buscando a melhoria contínua.

Oliveira Neto (2014), no estudo realizado em uma unidade de Laticínios localizada na região nordeste do estado do Rio Grande do Sul, objetivou avaliar o quanto o sistema APPCC é importante para implantação das ISO 22000. Verificou-se que o APPCC implantado satisfaz exigências de redução de perdas e aumento da competitividade por ser um programa que tem como filosofia a prevenção, satisfazendo à legislação nacional e internacional. Os Laticínios avaliados no presente estudo possuem os pré-requisitos para a implantação da norma ISO 22000.

No estudo realizado por Calheiros et al. (2010) em três empresas de Laticínios de pequeno porte, localizadas no interior de Minas Gerais, teve como objetivo analisar as iniciativas voltadas à gestão da qualidade na indústria de alimentos. O resultado obtido demonstrou que as empresas possuem conhecimento das ferramentas e metodologias, mas não têm claro o conceito de qualidade e não possuem programas básicos como APPCC e PPHO implantados, divergindo do resultado apresentado na presente pesquisa.

O fato da norma ISO 14001 estar em implantação na empresa A, de grande porte, confirma o relato de Chiab (2005) em seu estudo, onde as normas ISO 14001 e OHSAS 18001 têm sido utilizadas por empresas de grande porte, devido à disponibilidade de recursos financeiros e humanos para investimentos na implantação de sistemas de gestão ambiental e de saúde e segurança do trabalho.

Para Zaniolo (2015), na implantação do sistema APPCC realizada em um Laticínio de pequeno porte produtor de queijos tipo muçarela, localizado na cidade de Castanheira, MT, verificou-se a redução da carga microbiana encontrada durante o processo de fabricação, melhorando a qualidade da matéria-prima utilizada. Além disso, concluiu que o uso do sistema APPCC como ferramenta de qualidade mostrou-se efetivo na qualidade e segurança do produto final. Deste modo, destaca-se a importância das ferramentas de gestão da qualidade implantadas nos Laticínios em questão na região do Oeste de SC.

Santos et al. (2013) destaca a importância da gestão da qualidade dos produtos lácteos desde a matéria prima ao produto na prateleira, no estudo de caso realizado em um Laticínio no Sul da Bahia. Percebeu-se que a qualidade ainda não era prioridade da empresa, apesar de estar no planejamento a implementação futura de um manual de BPF. Nos Laticínios estudados no Oeste de SC todos contém este manual básico e tão importante para este setor.

Verificou-se neste estudo que todos os Laticínios estão investindo corretamente, adequando suas empresas nas normas de produção e qualidade, implementando na medida do possível todas as normas e sistemas exigidos e que minimizam possíveis causas de contaminação do leite ou derivados, evitando perdas de qualidade, garantindo a confiança e preferência do consumidor.

\section{CONCLUSÃO}

De acordo com o estudo realizado, podese identificar que os Laticínios estudados utilizam ferramentas e metodologias que auxiliam na gestão da qualidade dos seus 
produtos, possuem implantados os requisitos básicos da legislação brasileira vigente, podendo-se citar o BPF, MIP, PPHO e APPCC. Assim, estes Laticínios possuem as ferramentas básicas e fundamentais para a implantação de outros sistemas de qualidade, como por exemplo as ISO 9001 e ISO 22000. Apenas uma empresa, de grande porte, possuía a ISO 9001 implantada e em fase de implantação as ISO's 14001 e 22000 . Os outros Laticínios não possuem nenhum tipo de ISO implantada. Os Laticínios pesquisados buscam a manutenção da qualidade do produto, a padronização e a organização dos processos.

\section{REFERÊNCIAS}

BERSOT, L. S. et al. Quantificação de microrganismos indicadores de qualidade em leite cru refrigerado e comportamento da microbiota ao longo do transporte. Revista do Instituto de Laticínios Cândido Tostes, v. 65, n. 373, p. 9-13, 2010.

BRASIL. Ministério da Agricultura e do Abastecimento. Portaria $n^{\circ} 368$ de 04 de setembro de 1997. Regulamento técnico sobre as condições higiênico-sanitárias e de boas práticas de elaboração para estabelecimentos elaboradores/industrializadores de alimentos. Diário Oficial da República Federativa do Brasil: seção 1, Brasília, DF, n. 172, p. 19697, 08 set. 1997.

BRASIL. Ministério da Agricultura e do Abastecimento. Portaria $\mathrm{n}^{\circ} 46$, de 10 de fevereiro de 1998. Institui o sistema de análise de perigos e pontos críticos de controle: APPCC a ser implantado nas indústrias de produtos de origem animal. Diário Oficial da República Federativa do Brasil, Brasília, DF, 10 fev. 1998.

BRASIL. Ministério da Agricultura, Pecuária e Abastecimento. Instrução Normativa $n^{0}$ 51, de 18 de setembro de 2002. Regulamentos técnicos de produção, identidade e qualidade do leite tipo A, do leite tipo B, do leite tipo C, do leite pasteurizado e do leite cru refrigerado e o Regulamento técnico da coleta de leite cru refrigerado e seu transporte a granel. Diário Oficial da União: seção 1, Brasília, DF, n. 183, p. 13,20 set. 2002 .

BRASIL. Ministério da Agricultura, Pecuária e Abastecimento. Departamento de Inspeção de Produtos de Origem Animal. Resolução $n^{\circ}$ 10, de 22 de maio de 2003. Institui o Programa Genérico de Procedimentos - Padrão de Higiene Operacional - PPHO, a ser utilizado nos estabelecimentos de leite e derivados que funcionam sob o regime de Inspeção Federal. Diário Oficial da União: seção 1, Brasília, DF, n. 101 , p. 4, 28 mai. 2003.

BRASIL. Ministério da Agricultura, Pecuária e Abastecimento. Secretaria de Defesa Agropecuária. Instrução Normativa $\mathrm{n}^{\circ}$ 68, de 12 de dezembro de 2006. Oficializa os Métodos Analíticos Oficiais Físico-Químicos, para Controle de Leite e Produtos Lácteos Diário Oficial da União: seção 1, Brasília, DF, n. 239, p. 8, 14 dez. 2006.

BRASIL. Ministério da Agricultura, Pecuária e Abastecimento. Instrução Normativa $n^{\circ}$ 62, de 29 de dezembro de 2011. Aprova o Regulamento Técnico de Produção, Identidade e Qualidade do Leite tipo A, o Regulamento Técnico de Identidade e Qualidade de Leite Cru Refrigerado, o Regulamento Técnico de Identidade e Qualidade de Leite Pasteurizado e o Regulamento Técnico da Coleta de Leite Cru Refrigerado e seu Transporte a Granel. Diário Oficial da União: seção 1, Brasília, DF, n. 251, p. 6, 30 dez 2011 .

BRASIL. Ministério da Agricultura Pecuária e Abastecimento. Norma Interna DIPOA/SDA $n^{\circ}$ 01, de 08 de março de 2017. Aprova os modelos de formulários, estabelece as frequências e as amostragens mínimas a serem utilizadas na inspeção e fiscalização, para verificação oficial dos autocontroles implantados pelos estabelecimentos de produtos de origem 
animal registrados (SIF) ou relacionados (ER) junto ao DIPOA/SDA, bem como o manual de procedimentos. Diário Oficial da União, Brasília, DF, 2017(a).

BRASIL. Decreto ${ }^{\circ}$ 9.013, de 29 de março de 2017. Regulamenta a Inspeção Industrial e Sanitária de Produtos de Origem Animal. Diário Oficial da União: seção 1, Brasília, DF, n. 62, p. 3, 30 mar. 2017(b).

BRASIL. Ministério da Agricultura, Pecuária e Abastecimento. Instrução Normativa $n^{\circ} 76$, de 26 de novembro de 2018. Regulamentos Técnicos que fixam a identidade e as características de qualidade que devem apresentar o leite cru refrigerado, o leite pasteurizado e o leite pasteurizado tipo A. Diário Oficial da União: seção 1, Brasília, DF, n. 230, p. 9, 30 nov. 2018a.

BRASIL. Ministério da Agricultura, Pecuária e Abastecimento. Instrução Normativa $n^{\circ}$ 77, de 26 de novembro de 2018. Estabelece os critérios e procedimentos para a produção, acondicionamento, conservação, transporte, seleção e recepção do leite cru em estabelecimentos registrados no serviço de inspeção oficial Diário Oficial da União: seção 1, Brasília, DF, n. 230, p. 10, 30 nov. 2018b.

BRASIL. Ministério da Agricultura, Pecuária e Abastecimento. Ofício Circular no 24/2009/ GAB/DIPOA - Verificação dos programas de autocontrole de estabelecimentos sob Inspeção Federal processadores de leite e derivados, mel e produtos apícolas. Disponível em: http:// bemvin.org/ofcio-circular-n-24-2009-gabdipoabraslia-11-de-setembro-de-20.html Acesso em: 10 jun 2019.

BRASIL. Ministério da Agricultura, Pecuária e Abastecimento. Ofício Circular no 07 DILEI/ CGI/DIPOA - Procedimentos de verificação dos programas de autocontrole em estabelecimentos processadores de leite e derivados, mel e produtos apícolas. Disponível em http://bemvin.org/ ofcio-circular-n-24-2009-gabdipoa-braslia-11de-setembro-de-20.html Acesso em: 01 ago 2019.
BRASIL. Ministério da Agricultura, Pecuária e Abastecimento - MAPA. Registro. 2014. Disponível em: http//www.agricultura.gov.br/ vegetal/registros-autorizações/registro Acesso em 10 dez. 2018.

BRASIL. Ministério da Agricultura, Pecuária e Abastecimento. Serviço de Inspeção Federal - SIF. Disponível em: http://www.agricultura. gov.br/sif Acesso em: 16 de fev. 2016.

BSI, OHSAS 18001. Sistemas de Gestão de Saúde Ocupacional e Segurança: Diretrizes para a implementação da especificação OHSAS 18001. Reino Unido, 1999.

CALHEIROS, C. A. et al. Gestão de qualidade em pequenas empresas processadoras de leite: situação atual e recomendações. Revista do Instituto de Laticínios Cândido Tostes, v. 65, n. 374, p. 17-25, 2010.

CARMEN, E; VIJANDE, M. L. S. Reasons and constraints to implementing an ISO 22000 food safety management system: Evidence from Spain. Food Control, v. 40, p. 50-57, 2014.

CHIAB, E. B. D. Proposta para implementação de sistema de gestão integrada de meio ambiente, saúde e segurança do trabalho em empresas de pequeno e médio porte: um estudo de caso da indústria metal mecânica. Dissertação (Pós Graduação em Planejamento Energético) Universidade Federal do Rio de Janeiro, Rio de Janeiro, 2005.

DJORDJEVIC, D. et al. An analysis of the HACCP system implementation. The factor of improving competitiveness in Serbian companies. African Journal of Agricultural Research, v. 6, n. 3, p. 515-520, 2011.

FAO - Food and Agriculture Organization of the United Nations. 2012. Disponível em: http://faostat.fao.org/ Acesso em: 24 mai 2015.

FELTES, M. M. C; BRAGotTO, A. P. A.; BLOCK, J. M. Food quality, food-borne diseases, 
and food safety in the Brazilian food industry. Food Quality and Safety, v. 1, p. 13-27, 2017.

FIGUEIREDO, E. L; MELO, J. K. L; NEVES, N. C. O. Diagnóstico higiênico-sanitário e da qualidade microbiológica de produtos lácteos em um Laticínio localizado em Tucuruí-Pará. Revista do Instituto de Laticínios Cândido Tostes, v. 71, n. 2, p. 53-64, 2016.

FRANÇA, A. I. M. et al. Qualidade do leite cru refrigerado granelizado coletado no sudoeste goiano. Revista do Instituto de Laticínios Cândido Tostes. v. 70, n. 6, p. 316-325, 2015.

FREITAS, H. et al. O método de pesquisa survey. Revista de Administração, São Paulo, v. 35 , n. 3, p. 105-112, 2000.

IBGE. Instituto Brasileiro de Geografia e Estatísticas. Pesquisa trimestral do leite. Disponível em: https://www.ibge.gov.br/ estatisticas/economicas/agricultura-epecuaria/9209-pesquisa-trimestral-do-leite. html edicao $=23954 \& \mathrm{t}=$ destaques Acesso em: 28 nov. 2018.

OLIVEIRA NETO, F. A. Implantação do APPCC em um Laticínio para implantação da ISO 22000. Revista Especialize On-line IPOG, v. 01, n. 9, p. 8. 2014.

ORNELLAS, T. S. et al. Percepção de estudantes sobre a produção e qualidade do leite destinado ao consumo humano. In: SEAGRO - SEMANA ACADÊMICA DO CURSO DE AGRONOMIA DO CCAE/UFES, 28., 2017. Anais [...] Alegre: CCAE/UFES, 2017.

\section{SALCEDO, L. R. Validação dos procedimentos} de higienização de superfícies na indústria. 16 dez. 2016. Disponível em: https://www. milkpoint.com.br/industria/radar-tecnico/ higiene-industrial/sistema-de-higienizacao-cip- em-industria-de-leite-91724n.aspx Acesso em: 21 out. 2018 .

SANTOS, F. F. et al. Análise da gestão da qualidade em um laticínio: um estudo de caso. In: ENCONTRO NACIONAL DE ENGENHARIA DE PRODUÇÃO, 33., 2013, Salvador. Anais eletrônicos [...] Salvador: ABEPRO, 2013. Disponível em: http://www.abepro.org.br/ biblioteca/enegep2013_tn_stp_178_019_22644. pdf Acesso em: 21 out. 2018

SANTOS, G. L. LIMA, R. H. P. Proposta de um sistema integrado de gestão da qualidade e segurança alimentar para a indústria de Laticínios. In: ENCONTRO NACIONAL DE ENGENHARIA DE PRODUÇÃO, 31., 2011, Belo Horizonte. Anais eletrônicos [...] Belo Horizonte: ABEPRO, 2011. Disponível em: http://www.abepro.org.br/biblioteca/ enegep2011_tn_sto_136_864_18707.pdf

SCARDELATO, T. A., PAVÃO, J. A., CAMACHO, R. R. Integração entre gestão dos custos da qualidade e o custeio baseado em atividades: Um estudo no setor de controle de qualidade em uma empresa do ramo de laticínios. In: CONGRESSO BRASILEIRO DE CUSTOS, 24., 2017, Florianópolis. Anais eletrônicos [...] Florianópolis: ABC, 2017. Disponível em: https://anaiscbc.emnuvens.com.br/anais/article/ view/4255/4255 Acesso em: 08 nov. 2018.

USDA. Foreign Agricultural Service. Disponível em: http://apps.fas.usda.gov/ psdonline/ Acesso em: 10 nov. 2018.

ZANIOLO, J. A. Implantação do sistema APPCC na produção de queijo tipo muçarela. Enciclopédia Biosfera. Goiânia: Centro Científico Conhecer, v. 11, n. 22, p. 14411455, 2015. DOI: $10.18677 /$ Enciclopedia Biosfera_2015_173 